\title{
Continuous effectiveness and safety after a hospital-wide switch to adalimumab biosimilar: an observational study in rheumatoid arthritis patients
}

Rianne Brouwer

Medisch Spectrum Twente

Peter M. ten Klooster

University of Twente: Universiteit Twente

Joost B. Masselink

Medisch Spectrum Twente

Harald E. Vonkeman ( $\square$ h.e.vonkeman@utwente.nl)

University of Twente: Universiteit Twente https://orcid.org/0000-0003-3792-7718

Research article

Keywords: adalimumab, rheumatoid arthritis, biological therapies, switch, disease activity, biosimilar

Posted Date: March 17th, 2021

DOl: https://doi.org/10.21203/rs.3.rs-315232/v1

License: (c) (i) This work is licensed under a Creative Commons Attribution 4.0 International License. Read Full License 


\section{Abstract \\ Objectives}

Only few observational studies have investigated the actual effectiveness of switching to biosimilars in daily clinical practice in unselected patients. The objective of this study was to examine the maintenance of effect and safety after a hospital-wide switch for economic reasons from adalimumab originator Humira ${ }^{\circledR}$ to biosimilar Amgevita ${ }^{\circledR}$ in real-world rheumatoid arthritis (RA) patients and patient satisfaction with the switch.

\section{Methods}

A single centre retrospective observational study of RA patients on the course of their disease activity (DAS28, ESR and CRP), health-related quality of life (SF-36) and functional disability (HAQ-DI) before and up to one year after the switch, supplemented with a cross-sectional survey on satisfaction and experienced side effects approximately 18 months after the switch. Treatment outcomes were analysed with linear mixed modelling and generalized estimation equations.

\section{Results}

On November 1st 2018, 239 rheumatology patients switched to the adalimumab biosimilar. Of 52 RA patients who met the inclusion criteria sufficient data were available. Disease activity levels, the proportion of patients in remission (DAS28 $<2.6$ ), and SF-36 and HAQ-DI scores did not significantly change from before the switch. 38 of the 52 analysed patients returned the questionnaire. Overall, patients were satisfied with the switch. Three patients (7.9\%) stopped the biosimilar due to side effects.

\section{Conclusion}

Switching to the adalimumab biosimilar did not result in increased disease activity or worse patientreported outcomes over an observation period of 9 to 12 months. Also, there was no apparent evidence of increased side effects. Patients themselves were mostly satisfied with the switching experience.

\section{Key Messages}

- Switching to an adalimumab biosimilar was well tolerated in RA patients.

- Overall, patients were satisfied with the switch.

- Switching from biological to biosimilar can create a reduction of healthcare costs.

\section{Introduction}


The first biological for the treatment of rheumatoid arthritis (RA), etanercept (Enbrel $\circledast$ ), was approved by the United States Food and Drug Administration (FDA) in 1998 [1]. The introduction of biologicals has ensured better treatment options for RA [2-4], but at a price. The high share of biologicals in the overall costs of RA treatment is clearly illustrated in a Swedish study on the development of healthcare costs for RA from 1990 to 2010 [5]. In twenty years, the total costs had risen from $€ 454$ million to $€ 600$ million, while the overall number of hospital admissions and indirect medical costs had been reduced. It turned out that in $2010,33 \%$ of the healthcare costs for RA were related to costs for drugs, compared to only $3 \%$ in 1990. Ninety percent of these costs were due to biologicals, a percentage that still seemed to be increasing in 2010 [5]. The top three of most expensive medicines based on total expenditure in 2016 [6] in the Netherlands also clearly reflects the relatively high cost of biologicals, as it comprised the three biologicals most frequently used in RA; adalimumab ( $€ 216$ million), etanercept ( $€ 143$ million) and infliximab (€140 million) [6, 7].

Given the very high costs and associated high yields of biologicals, more and more biosimilars are being marketed with the expiration of biological innovator patents [8-10]. In September 2013 the first biosimilars for use in RA treatment were approved by the European Medicines Agency (EMA), namely Inflectra ${ }^{\circledR}$ and Remsima ${ }^{\circledR}$ [8], both infliximab biosimilars. In the years that followed, more biosimilars of different biologicals were approved and many more are in the pipeline [9].

Prior to FDA and EMA approval of biosimilars, several studies need to have demonstrated biological similarity between the biosimilar and the reference product, including at least one trial demonstrating equivalent efficacy in an appropriate patient population [9]. If biosimilarity has been demonstrated, it is assumed that the efficacy and safety of the biosimilar remain highly comparable to those of its originator over time. Subsequent approval of biosimilars thus requires only limited testing of efficacy and safety compared to those required for approval of bio-originators [11].

After the various biosimilars had been marketed, some large switch studies have been carried out to investigate the efficacy and safety of switching from a bio-originator to a biosimilars in RA patients. The PLANETRA extension study [12] and the NOR-SWITCH study [13], focussed on infliximab and its biosimilars, the DANBIO study [14], focussed on etanercept, and an extension study of a trial evaluated switching from adalimumab to Imraldi ${ }^{\circledR}[15]$. These studies all indicated no loss of efficacy or increase in adverse events after switching. Consequently, switching from a bio-originator to one of its biosimilars if the biosimilar costs less than its originator is considered a safe and effective option in clinical practice [11]. However, this recommendation has also been questioned since most of the evidence to date is based on extensions of randomised controlled trials in selected patients, like the PLANETRA and Imraldi® extension studies $[16,17]$, which may not be comparable to patients treated in the setting of real-world practice [18]. Moreover, little is known yet about patients' satisfaction and experience with switching to a biosimilar.

In October 2018, the patent of the adalimumab originator Humira ${ }^{\circledR}$ expired [19], which created an opportunity to switch adalimumab users to a less expensive biosimilar. On November 1st 2018, after 
being fully informed in the prior weeks, all patients attending a large teaching hospital in the Netherlands who were using the adalimumab originator were switched to biosimilar Amgevita ${ }^{\circledR}$. The aim of this retrospective observational study is to examine RA patients' disease activity, health-related quality of life and functional disability before and after the switch and patient-reported side effects and satisfaction after the switch.

\section{Method}

\section{Study design}

This retrospective observational single centre study was performed at the rheumatology department of the Medisch Spectrum Twente hospital in Enschede, the Netherlands. On November 1st 2018, all patients who were using the adalimumab originator Humira ${ }^{\circledR}$ were switched to biosimilar Amgevita ${ }^{\circledR}$ for economic reasons.

To ensure a safe and smooth switch, a hospital committee consisting of a rheumatologist, hospital pharmacist, PR officer, and a member of the budget committee was formed.

This committee was responsible for planning, communication to prescribers and patients, implementation, and monitoring the switch. In consultation with different prescribers (e.g. rheumatologists, gastroenterologists, dermatologists) an information letter was sent to all patients informing about the upcoming switch and the reason for the switch. In this letter a reference to a FAQ list at the website of the teaching hospital was mentioned as well as a telephone number that was available during office hours where information about the switch could be obtained if needed.

To investigate the continuous effectiveness and safety of this switch in the involved RA patients, retrospective data already available from various databases was supplemented with a questionnaire survey. Clinical data were obtained from MijnReumacentrum.nl, an online patient registry in which clinical and patient reported outcome data from patients with rheumatological diseases are systematically collected, the hospital's electronic patient files, and pharmacy dispensing data of adalimumab, obtained through the hospital pharmacy department. Additional data on possible side effects and patient satisfaction were collected through a cross-sectional questionnaire in the study sample. Since most data in the study had already been collected in the course of daily clinical care and patients were neither subject to procedures nor required to follow rules of behaviour, the study does not fall under the Dutch Medical Research Involving Human Subjects Act (WMO), the study was thus exempt from review by an accredited medical ethics committee. All patients included in MijnReumacentrum.nl have provided active informed consent to use their data for clinical research.

\section{Patient selection}

Eligible patients were selected by cross referencing two datasets; a dataset from MijnReumacentrum.nl with all RA patients using adalimumab on May 1, 2018 and a dataset from the hospital pharmacy with all adalimumab dispenses between July 1, 2018 and February 26, 2020. Both datasets were compared on 
patient identification numbers. Remaining patients were eligible for inclusion if they: 1) had been diagnosed with RA by a rheumatologist, 2) were at least eighteen years of age on November 1, 2018, and

3 ) had used the adalimumab originator biological for at least three months before the hospital wide switch to the adalimumab biosimilar. Patients were excluded if: 1) they had a rheumatologic diagnosis other than RA, 2) there were no data of the patient in MijnReumacentrum.nl, 3) there was no DAS28 score available in the six months before and/or after the switch, 4) no adalimumab dispense was registered at the hospital pharmacy or if the use of adalimumab started after November 1,2018,5) adalimumab was discontinued before November 1,2018 , or 6 ) there was no apparent consistent adalimumab use in the three months before the switch.

\section{Assessments}

The primary endpoint of this study was change in mean disease activity measured by the 28-joint Disease Activity Score (DAS28), a composite index consisting of 28 joint counts for tender and swollen joints, the erythrocyte sedimentation rate (ESR) and a 0-100 visual analogue scale of general health (VASGH) [20]. Secondary endpoints were the number of patients in DAS28 remission (DAS28 <2.6) [21] and number of increases in disease activity larger than the measurement error $(\triangle D A S 28>0.6)$ or flares $(\triangle D A S 28 \geq 1.2)$ between two consecutive measurements [22]. Other secondary endpoints were the inflammatory markers ESR and C-reactive protein (CRP), physical and mental health-related quality of life as expressed by the norm-based physical and mental component summary scores of the Short Form-36 version 2 (SF-36 Physical Component Score (PCS) and SF-36 Mental Component Score (MCS)) [23, 24], functional disability measured with the Health Assessment Questionnaire Disability Index (HAQ-DI) [25, 26], general health (VAS-GH), and the number of patients switching back to the adalimumab originator biological, patient-reported side effects and patient satisfaction regarding the switch. These last three outcomes were measured by means of an additional short self-developed questionnaire in the study sample (Appendix 1).

\section{Data set structure}

Because appointments for RA patients mostly take place every three to six months, the DAS28, VAS-GH and CRP and ESR measurements of $3( \pm 1.5), 6( \pm 1.5), 9( \pm 1.5)$ and $12( \pm 1.5)$ months before and after the switch date were included in the data set. The baseline measurement was selected as the measurement available closest before the switch. Due to fewer available HAQ-DI, SF-36 PCS and SF-36 MCS measurements, we decided to limit these data to a baseline measurement and a measurement 3 and 9 months after the switch.

\section{Statistical analyses}

All statistical tests were performed in IBM SPSS Statistics Version 26 and results were considered significant at $p<0.05$. Normally distributed continuous outcomes over time were analysed by repeated measures linear mixed modelling with time point as fixed effect and compound symmetry as the covariance structure for the repeated measurements as this provided the best fit for most models. The proportion of patients in remission was analysed as a binary logistic dependent variable by generalized 
estimation equations with an exchangeable correlation matrix for repeated observations. Non-normally distributed continuous variables, which also didn't become normally distributed by taking the natural logarithm, were recoded to a dichotomous variable. CRP values were divided into $\leq 10$ and $>10 \mathrm{mg} / \mathrm{L}$ for normal and elevated levels and the VAS-GH into $\leq 20$ and $>20$ for satisfactory and unsatisfactory levels, respectively $[27,28]$. Post-hoc analyses of differences from the baseline measurement were done with Fisher least significant difference (LSD) tests to correct for multiple comparisons. Clinically relevant increases of the DAS28 between two consecutive measurements and the results of the additional crosssectional questionnaire were analysed descriptively.

\section{Results}

\section{Patient selection}

239 unique patients were selected from the datasets. Based on the in- and exclusion criteria, 52 patients were included for analysis. The most important reasons for exclusion were having another rheumatic disease and a start date of adalimumab after November 1, 2018 (Fig. 1).

\section{Baseline characteristics}

The mean $( \pm S D)$ age of the included patients was $62.4( \pm 10.8)$ years and over $80 \%$ of the population was female (Table 1). The median ( \pm IQR) RA disease duration was $15( \pm 11)$ years. The majority of patients were rheumatoid factor and/or anti-CCP positive, respectively $86.5 \%$ and $73.1 \%$. On average, patients had used the originator biological for almost 88 months, of which on average 36 months was continuous use before the switch to the biosimilar. Mean DAS28 at baseline measurement was 2.25 ( \pm $0.81)$. The majority of patients $(69.2 \%)$ were in DAS28 remission. 
Table 1

Baseline demographics and disease characteristics

Variable

Age in years, mean (SD)

Female sex, n (\%)

Rheumatoid factor positive, $\mathrm{n}(\%)$

Anti-CCP positive, $\mathrm{n}(\%)^{\mathrm{a}}$

Duration of RA in years, median (IQR)

Total duration of Humira ${ }^{\circledR}$ use in months, mean (SD)

Continuous Humira ${ }^{\circledR}$ use before switch in months, median (IQR)

DAS28, mean (SD)

DAS28 categories, $\mathrm{n}(\%)$

Remission

Low disease activity

Moderate disease activity

High disease activity

ESR, median (IQR)

CRP, median (IQR)

VAS-GH, median (IQR)

SF-36 PCS, mean (SD)

SF-36 MCS, mean (SD)

HAQ-DI, mean (SD)

\section{Value}

$62.4(10.8)$

$42(80.8)$

45 (86.5)

$38(73.1)$

$15(11)$

$87.8(47.5)$

36.1 (45.5)

$2.25(0.81)$

$36(69.2)$

10 (19.2)

$6(11.5)$

$0(0.0)$

$12(17)$

2 (4)

20 (30)

$41.55(7.40)$

$48.52(9.71)$

$0.76(0.55)$

a missing $n=6(11.5 \%)$. Anti-CCP = anti-cyclic citrullinated peptide antibody, DAS28 $=28$-joint Disease Activity Score, ESR = erythrocyte sedimentation rate, $\mathrm{CRP}=\mathrm{C}$-reactive protein, VAS-GH = visual analogue scale of general health, SF-36 PCS = Short Form-36 Physical Component Summary, SF-36 MCS = Short Form-36 Mental Component Summary, HAQ-DI = Health Assessment Questionnaire Disability Index.

\section{Disease activity}

The mean DAS28 score over time was fairly stable and didn't show a significant difference between the baseline measurement (mean DAS28 $=2.25$ ) and the measurement three months after the switch (mean DAS28 $=2.29 ; p=0.780$ ). Also, no significant differences were observed at the group level between the baseline measurement and the measurements 6, 9 and 12 months after the switch (Fig. 2). The 
percentage of patients in remission at the baseline measurement was $69 \%$. Over the following months, this percentage dropped to $58 \%$ at 9 months after the switch, but this difference was not significant $(p=$ 0.209; Fig. 2).

In the complete data set, there were 54 increases of the DAS $28 \geq 0.6$ between two consecutive measurements and in fifteen cases this was a flare (DAS28 increase $\geq 1.2$ ). In 21 of these 54 cases (38.9\%), the category of disease activity remained the same. In 3 of the 15 flares (20\%) the category of disease activity also remained the same. Before the switch to the biosimilar there were 23 increases of the DAS28 $\geq 0.6(12.5 \%), 6$ of them (3.3\%) were flares. After the switch 31 increases of the DAS28 $\geq 0.6$ (15.9\%) occurred, of which nine were flares (4.6\%). Thus, after the switch slightly more relevant increases in DAS28 were observed than before the switch.

\section{Markers of inflammation}

Mean ESR values fluctuated only marginally over time (Fig. 3). Mean ESR was highest 9 months before the switch (mean $=13.74$ ) and lowest 12 months after the switch (mean $=10.70, p=0.052$ ). CRP values also showed no significant differences between baseline and the subsequent measurements.

\section{Patient-reported outcome measures}

Mean scores of the SF-36, HAQ-DI and VAS-GH over time are shown in Fig. 4. As with the DAS28, the mean scores of health-related quality of life and functional disability were not significantly different before and after the switch. The proportion of patients reporting satisfactory general health (VAS-GH $\leq$ 20) was also not significantly different from baseline at any of the measurement times after the switch.

\section{Safety}

38 of the 52 patients returned the survey. Thirty-two (84.2\%) of them reported that they were still using the adalimumab biosimilar and six (15.8\%) declared that they discontinued the biosimilar. Three patients (7.9\%) discontinued the biosimilar because of side effects; one of which switched back to the originator biological due to a severe malaise for 14 days after one injection of the biosimilar. One patient discontinued because of herpes zoster after one injection with the biosimilar and one patient because of developing lupus erythematosus after one year of treatment. Of the other three patients who discontinued the biosimilar, one patient discontinued because of fearing the coronavirus whilst having few rheumatic complaints and two other patients discontinued because of persistent remission.

A total of twelve patients (31.6\%) reported side effects. Besides the side effects mentioned above other side effects mentioned in the survey were; occasionally oral sores, inflammation of the eyelid, cystitis, flulike symptoms, urticaria, fatigue, coughing, bruising at the injection site and generally feeling ill for almost six months. All side effects were reported only once and all by different patients.

\section{Satisfaction}

Overall, patients were satisfied with the switch. 
On a scale of 0 to 10 , where 0 meant 'totally disagree' and 10 'totally agree', the mean score for the statement 'I am satisfied with the switch' was $7.53( \pm 2.78)$.

Twenty-three patients gave a score of 8 or higher while only six patients gave a score of 5 or less. However, despite not being fully satisfied with the switch, only three of them discontinued the biosimilar.

The mean score for the statement 'I have received sufficient information prior to the switch' was 7.84 ( \pm 2.32). For the statement 'I knew where to go with questions' the mean score was $8.62( \pm 1.82)$ and the statement 'I felt sufficiently prepared for the switch' scored $7.76( \pm 2.27)$. Only a few patients gave scores below 5 on any of the questions.

Regarding the ease of use and functioning of the Amgevita ${ }^{\circledR}$ syringe, it was reported three times that the Amgevita ${ }^{\circledR}$ injection is slightly more painful than the Humira ${ }^{\circledR}$ injection. In addition, there were three reports of intermittent failure of the syringe, one patient mentioned that the syringe did not always click after the injection is completed and one patient mentioned that he was unable to see the screen properly because of the location of the thumb notch.

\section{Discussion}

On November 1st 2018, after being fully informed in the prior weeks, all patients attending a large teaching hospital in the Netherlands who were using the adalimumab originator were switched to the biosimilar Amgevita ${ }^{\circledR}$ for economic reasons. No significant loss of effectiveness or unsuspected safety issues were observed among switched RA patients. Most patients were satisfied with the switch and continued treatment with the biosimilar. These findings are consistent with findings from previous switch studies [13-16] and a trial in which the efficacy and safety of Amgevita ${ }^{\circledR}$ was compared to that of Humira ${ }^{\circledR}[29]$.

In the current study there was a small numerical increase in the number of relevant disease activity increases and flares between consecutive measurements of the DAS28 before and after the switch. However, mean disease activity scores were not significantly different from the measurement before the switch and most patients remained in the same category of disease activity throughout the observation period. The percentage of patients who ended up in a different category of disease activity due to an increase in DAS28 scores was the same before and after the switch, $60.9 \%$ and $61.3 \%$ respectively. In the majority of cases, the DAS28 score had decreased again by the next measurement, so patients were not in a higher category of disease activity for a long time.

Based on the survey, $7.9 \%$ of the patients discontinued the biosimilar for reasons other than being in remission. This is slightly lower than in other large switch studies like the PLANETRA extension crossover study [16], in which $11.1 \%$ discontinued, excluding patients who discontinued because of remission, and the Humira ${ }^{\circledR}$ to Imraldi ${ }^{\circledR}$ switch study [15], in which $8.5 \%$ discontinued, excluding patients who discontinued because of remission, and the DANBIO-study [14], in which 18.0\% discontinued, including patients who discontinued because of remission. 
In the current study, only one patient switched back to the originator adalimumab. In an open-label switch study of a etanercept biosimilar, $2.72 \%$ of the 625 patients switched back to the originator biological [30], in the DANBIO study $6.42 \%$ of the 1621 patients switched back to the originator biological [14] and in an open label switch study by Tweehuysen et al. $18.9 \%$ of the 192 patients switched back to their originator biological [31]. Notably, the high percentage of patients who switched back to the originator biological in the study by Tweehuysen et al. seemed to be mainly due to subjective complaints. The percentage of patients that reported side effects in the current study was also relatively low. Twelve patients (31.6\%) reported side effects, which led to discontinuation of Amgevita ${ }^{\circledR}$ in three patients. In the large comparison trial by Cohen et al. [29] $50 \%$ of the Amgevita ${ }^{\circledR}$ users and $54.6 \%$ of the Humira ${ }^{\circledR}$ users reported any kind of side effect The study population in the current study, however, might be too small to provide accurate estimations.

We started the patient selection with 239 unique patients who had switched from the originator biological adalimumab to the biosimilar adalimumab. Because of the strict selection criteria with a focus on RA patients only, 52 patients were available for analysis. Although this is a relatively small size, this approach did improve the quality of the data and the external validity of the findings for typical real-world RA patients.

The combined use of clinical data, patient-reported outcome data and pharmacy dispensing data is another strength of this study. By combining clinical and pharmacy data for the patient selection, we could accurately determine the exact switch date for the individual patients and patient medication compliance could be reasonably assessed. In addition, this study specifically examined the satisfaction of patients themselves with the course of the switch and the use of the Amgevita ${ }^{\circledR}$ syringe. In other switch studies little or no attention has been paid to these patient experiences, while it can lead to new insights and improvements. Combining the different clinical databases and also examining patient experiences offers a unique complete view of what a hospital-wide switch to a biosimilar means to patients.

The study also has some limitations. The reported side effects atributed to Amgevita ${ }^{\circledR}$ are completely based on the patients' reports and were not clinically verified. Secondly, this study is a retrospective observational study, with consequently some missing data and a higher possibility of bias. In patients knowing they are receiving a biosimilar, there may be a greater chance of a nocebo effect [32]. The way information is conveyed in case of a potential switch can also contribute to a nocebo effect [33]. By avoiding negative associations, one can keep the nocebo effect as small as possible [34]. However, the development of negative associations cannot be fully controlled and can always influence the outcomes to some extent. For example, people may look up information by themselves and care workers cannot fully control what patients read and how they interpret this. Especially the lower costs of biosimilars may influence negative associations [35].

With a total expenditure of $€ 216$ million in 2016, the Netherlands annually spent most on the drug adalimumab of all biologicals [6, 7]. Due to the expiration of patents, room is created on the market for 
biosimilars, which are usually cheaper and can therefore contribute to lowering healthcare costs. In daily practice, the advent of biosimilars often means that newly starting patients are prescribed the biosimilar, while patients who are already using the originator biological continue to use the originator. By demonstrating in the current study that patients who are already using an originator biological can effectively and safely switch to a biosimilar, the decision to switch these patients to the biosimilar may be made more often in the future. This can further help to reduce healthcare costs and keeping healthcare accessible for everyone.

In conclusion, in patients with RA, switching from Humira ${ }^{\circledR}$ to Amgevita ${ }^{\circledR}$ for economic reasons did not significantly increase disease activity or impairments in physical function and did not decrease quality of life over an observation period of 12 months. Also, there was no apparent indication of increased side effects. Patients themselves were mostly satisfied with the switch.

\section{Abbreviations}

Anti-CCP Anti-cyclic citrullinated peptides

CRP C-Reactive Protein

DAS28 28 joints Disease Activity Score

EMA European Medicine Agency

ESR Erythrocyte Sedimentation Rate

FDA U.S. Food \& Drug Administration

HAQ-DI Health Assessment Questionnaire Disability Index

LSD Least Significant Difference

MCS Mental Component Score

PCS Physical Component Score

RA Rheumatoid Arthritis

SF-36 Short Form 36

VAS-GH Visual Analogue Scale of General Health

WMO Dutch Medical Research Involving Human Subjects Act

\section{Declarations}


Ethics approval and consent to participate: According to the Dutch Medical Research Involving Human Subjects Act, the survey study did not need formal approval of a medical ethical review board, as it was a non-intervention study without a high burden to patients. However all patients were informed about the purpose of the study and the voluntary nature of participation.

Consent for publication: Not applicable.

Availibility of data and materials: The datasets generated and analyzed for the current study are not publicly available due to legal restrictions related to data privacy protection but are available from the corresponding author on reasonable request.

Competing interests: The authors declare that they have no competing interests.

Funding: No specific funding was received from any bodies in the public, commercial or not-for-profit sectors to carry out the work described in this article.

Authors' contribution: PK, HV and JM were responsible for the conceptualization of this study. PK and HV further devised the methods. RB did the formal analyses and investigation and the original draft preparation. The writing, reviewing and editing was conducted by all four of the authors.

Acknowledgement: Mirjam C. Hegeman ${ }^{1}$, research coordinator rheumatology department, for organising the data collection

\section{References}

1. Curtis JR, Singh JA. Use of Biologics in Rheumatoid Arthritis: Current and Emerging Paradigms of Care. Clin Ther. 2011;33(6):679-707. https://doi.org/10.1016/j.clinthera.2011.05.044

2. Klareskog L, van der Heijde D, de Jager JP, Gough A, Kalden J, Malaise M, et al. Therapeutic effect of the combination of etanercept and methotrexate compared with each treatment alone in patients with rheumatoid arthritis: double-blind randomised controlled trial. Lancet. 2004;363(9410):675-81. https://doi.org/10.1016/S0140-6736(04)15640-7

3. St.Clair EW, Van Der Heijde DMFM, Smolen JS, Maini RN, Bathon JM, Emery P, et al. Combination of infliximab and methotrexate therapy for early rheumatoid arthritis: A randomized, controlled trial. Arthritis Rheum. 2004;50(11):3432-43. https://doi.org/10.1002/art.20568

4. Breedveld FC, Weisman MH, Kavanaugh AF, Cohen SB, Pavelka K, Van Vollenhoven R, et al. The PREMIER study: A multicenter, randomized, double-blind clinical trial of combination therapy with adalimumab plus methotrexate versus methotrexate alone or adalimumab alone in patients with early, aggressive rheumatoid arthritis who had not had previo. Arthritis Rheum. 2006;54(1):26-37. https://doi.org/10.1002/art.21519

5. Kalkan A, Hallert E, Bernfort L, Husberg M, Carlsson P. Costs of rheumatoid arthritis during the period 1990-2010: A register-based cost-of-illness study in Sweden. Rheumatol (United Kingdom). 
2014;53(1):153-60. https://doi.org/10.1093/rheumatology/ket290

6. Nederlandse Zorgautoriteit. Geneesmiddelen in de medisch-specialistische zorg. [Internet]. 2019. Available from: https://puc.overheid.nl/nza/doc/PUC_264248_22/1/

7. Zorginstituut Nederland. Biologicals, 2015-2019 [Internet]. [cited 2020 Aug 25]. Available from: https://www.gipdatabank.nl/databank?infotype=g\&label=00totaal\&tabel=04_addon\&geg=vg\&item=b-Biologicals

8. Thomas D, Strand V, Cornes P, Gonçalves J, Gulácsi L, Kay J, et al. The changing landscape of biosimilars in rheumatology. Ann Rheum Dis. 2016;75(6):974-82. http://dx.doi.org/10.1136/annrheumdis-2016-209166

9. Smolen JS, Goncalves J, Quinn M, Benedetti F, Lee JY. Era of biosimilars in rheumatology: Reshaping the healthcare environment. RMD Open. 2019;5(1):900. http://dx.doi.org/10.1136/rmdopen-2019000900

10. Scheinberg $M$, Azevedo $V$. The future landscape of biosimilars in rheumatology: Where we are where we are going. Vol. 18, Autoimmunity Reviews. 2019. p. 203-8. https://doi.org/10.1016/j.autrev.2018.09.005

11. Kay J, Schoels MM, Dörner T, Emery P, Kvien TK, Smolen JS, et al. Consensus-based recommendations for the use of biosimilars to treat rheumatological diseases. Ann Rheum Dis. 2018;77(2):165-74. http://dx.doi.org/10.1136/annrheumdis-2017-211937

12. Yoo DH, Racewicz A, Brzezicki J, Yatsyshyn R, Arteaga ET, Baranauskaite A, et al. A phase III randomized study to evaluate the efficacy and safety of CT-P13 compared with reference infliximab in patients with active rheumatoid arthritis: 54-week results from the PLANETRA study. Arthritis Res Ther. 2016;18(1):1-12. https://doi.org/10.1186/s13075-016-0981-6

13. Jørgensen KK, Olsen IC, Goll GL, Lorentzen M, Bolstad N, Haavardsholm EA, et al. Switching from originator infliximab to biosimilar CT-P13 compared with maintained treatment with originator infliximab (NOR-SWITCH): a 52-week, randomised, double-blind, non-inferiority trial. Lancet. 2017;389(10086):2304-16. https://doi.org/10.1016/S0140-6736(17)30068-5

14. Glintborg B, Loft AG, Omerovic E, Hendricks O, Linauskas A, Espesen J, et al. To switch or not to switch: Results of a nationwide guideline of mandatory switching from originator to biosimilar etanercept. One-year treatment outcomes in 2061 patients with inflammatory arthritis from the DANBIO registry. Ann Rheum Dis. 2019;78(2):192-200. http://dx.doi.org/10.1136/annrheumdis2018-213474

15. Weinblatt ME, Baranauskaite A, Dokoupilova E, Zielinska A, Jaworski J, Racewicz A, et al. Switching From Reference Adalimumab to SB5 (Adalimumab Biosimilar) in Patients With Rheumatoid Arthritis: Fifty-Two-Week Phase III Randomized Study Results. Arthritis Rheumatol. 2018;70(6):832-40. https://doi.org/10.1002/art.40444

16. Yoo DH, Prodanovic N, Jaworski J, Miranda P, Ramiterre E, Lanzon A, et al. Efficacy and safety of CTP13 (biosimilar infliximab) in patients with rheumatoid arthritis: Comparison between switching from 
reference infliximab to CT-P13 and continuing CT-P13 in the PLANETRA extension study. Ann Rheum Dis. 2017;76(2):355-63. http://dx.doi.org/10.1136/annrheumdis-2015-208786

17. Weinblatt ME, Baranauskaite A, Niebrzydowski J, Dokoupilova E, Zielinska A, Jaworski J, et al. Phase III Randomized Study of SB5, an Adalimumab Biosimilar, Versus Reference Adalimumab in Patients With Moderate-to-Severe Rheumatoid Arthritis. Arthritis Rheumatol. 2018;70(1):40-8. https://doi.org/10.1002/art.40336

18. Cantini F, Benucci M. Switching from the bio-originators to biosimilar: Is it premature to recommend this procedure? Ann Rheum Dis. 2019;78(4):e23-e23. http://dx.doi.org/10.1136/annrheumdis-2017212820

19. Storz U. Of patents and patent disputes: The TNFa patent files. Part 1: Humira. Hum Antibodies. 2017;25(1-2):1-16. https//doi.org/10.3233/HAB-160300

20. Prevoo ML, van 't Hof MA, Kuper HH, van Leeuwen MA, van de Putte LB, van Riel PL. Modified Disease Activity Scores that include twenty-eight-joint counts: development and validation in a prospective longitudinal study of patients with rheumatoid arthritis. Arthritis Rheum. 1995;38(1):448. https://doi.org/10.1002/art.1780380107

21. Fransen J, Creemers MC, Van Riel PL. Remission in rheumatoid arthritis: agreement of the disease activity score (DAS28) with the ARA preliminary remission criteria. Rheumatol. 2004;43(10):1252-5. https://doi.org/10.1093/rheumatology/keh297

22. van der Maas A, Lie E, Christensen R, Choy E, de Man YA, van Riel P, et al. Construct and criterion validity of several proposed DAS28-based rheumatoid arthritis flare criteria: an OMERACT cohort validation study. Ann Rheum Dis. 2013;72(11):1800-5. http://dx.doi.org/10.1136/annrheumdis2012-202281

23. Jr JEW. SF-36 Health Survey Update. 2004;3:693-718. https://doi.org/10.1097/00007632200012150-00008

24. ten Klooster PM, Vonkeman HE, Taal E, Siemons L, Hendriks L, de Jong AJL, et al. Performance of the Dutch SF-36 version 2 as a measure of health-related quality of life in patients with rheumatoid arthritis. Heal Qual Life Outcomes. 2013;11:77. https://doi.org/10.1186/1477-7525-11-77

25. Fries JF, Spitz PW, Young DY. The dimensions of health outcomes: the Health Assessment Questionnaire, disability and pain scales. J Rheumatol. 1982;9(5):789-93.

26. ten Klooster PM, Taal E, van de Laar MA. Rasch analysis of the Dutch Health Assessment Questionnaire disability index and the Health Assessment Questionnaire II in patients with rheumatoid arthritis. Arthritis Rheum. 2008;59(12):1721-8. https://doi.org/10.1002/art.24065

27. Wells GA, Boers M, Shea B, Brooks PM, Simon LS, Strand C V, et al. Minimal disease activity for rheumatoid arthritis: a preliminary definition. J Rheumatol. 2005;32(10):2016-24.

28. Poole CD, Conway P, Reynolds A, Currie CJ. The association between C-reactive protein and the likelihood of progression to joint replacement in people with rheumatoid arthritis: A retrospective observational study. BMC Musculoskelet Disord. 2008;9(1):146. https://doi.org/10.1186/1471-2474$9-146$ 
29. Cohen S, Genovese MC, Choy E, Perez-Ruiz F, Matsumoto A, Pavelka K, et al. Efficacy and safety of the biosimilar ABP 501 compared with adalimumab in patients with moderate to severe rheumatoid arthritis: A randomised, double-blind, phase III equivalence study. Ann Rheum Dis. 2017;76(10):1679-87. http://dx.doi.org/10.1136/annrheumdis-2016-210459

30. Tweehuysen L, Huiskes VJB, van den Bemt BJF, Vriezekolk JE, Teerenstra S, van den Hoogen FHJ, et al. Open-Label, Non-Mandatory Transitioning From Originator Etanercept to Biosimilar SB4. Arthritis Rheumatol. 2018 Sep;70(9):1408-18. https://doi.org/10.1002/art.40516

31. Tweehuysen $L$, van den Bemt BJF, van Ingen IL, de Jong AJL, van der Laan WH, van den Hoogen FHJ, et al. Subjective Complaints as the Main Reason for Biosimilar Discontinuation After OpenLabel Transition From Reference Infliximab to Biosimilar Infliximab. Arthritis Rheumatol. 2018;70(1):60-8. https://doi.org/10.1002/art.40324

32. Odinet JS, Day CE, Cruz JL, Heindel GA. The Biosimilar Nocebo Effect? A Systematic Review of Double-Blinded Versus Open-Label Studies. J Manag care Spec Pharm. 2018;24(10):952-9. https://doi.org/10.18553/jmcp.2018.24.10.952

33. Tweehuysen L, Huiskes V, Bemt B van den, Hoogen F van den, Broeder A den. Higher acceptance and persistence rates after biosimilar transitioning in patients with a rheumatic disease after employing an enhanced communication strategy. Arthritis Rheumatol. 2017;74(Suppl2):557. http://dx.doi.org/10.1136/annrheumdis-2017-eular.2889

34. Colloca L, Panaccione R, Murphy TK. The clinical implications of nocebo effects for biosimilar therapy. Front Pharmacol. 2019;10:1372. https://doi.org/10.3389/fphar.2019.01372

35. Waber RL, Shiv B, Carmon Z, Ariely D. Commercial features of placebo and therapeutic efficacy. JAMA. 2008;299(9):1016-7. https://doi.org/10.1001/jama.299.9.1016

\section{Figures}




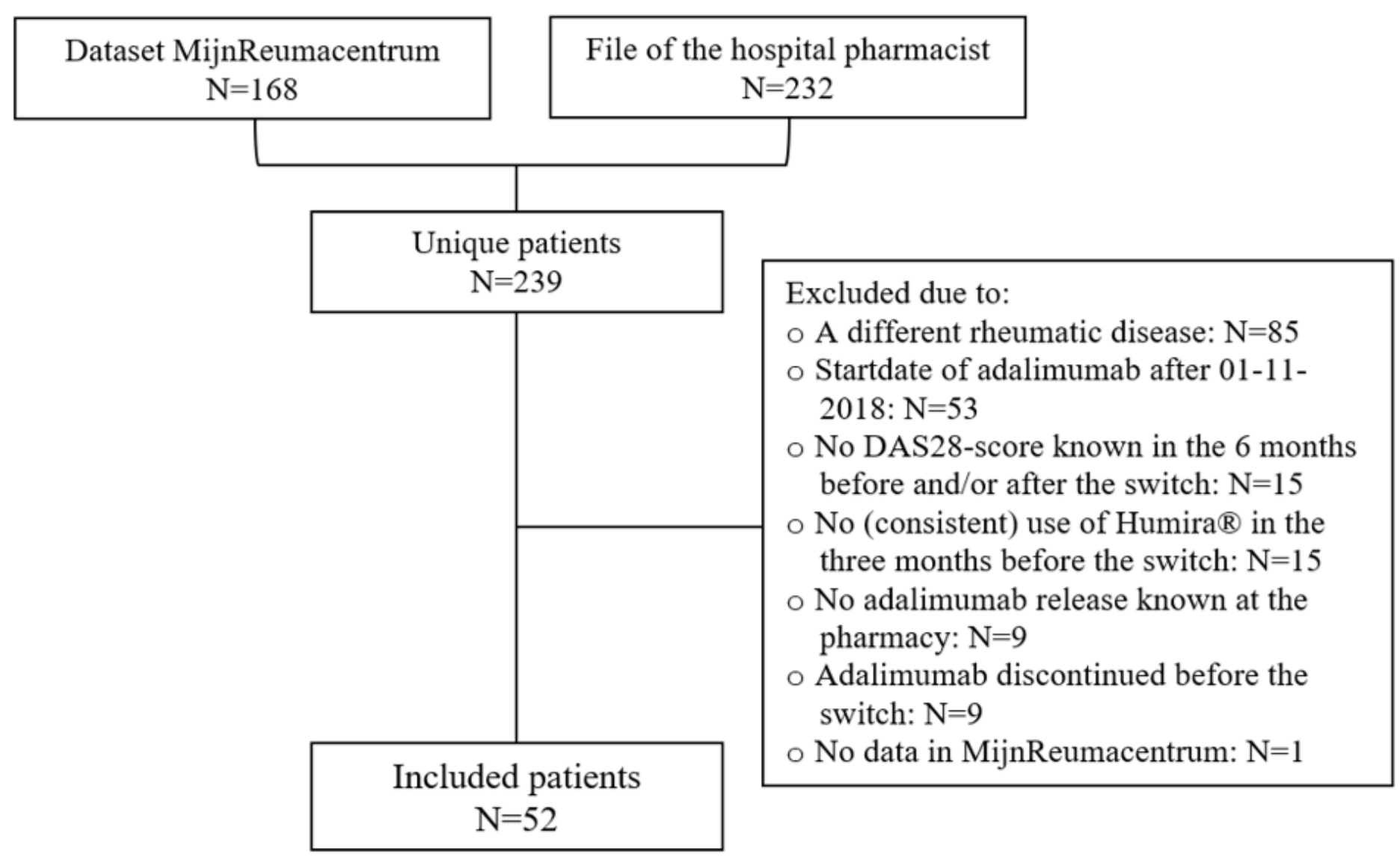

Figure 1

Flowchart patient selection. DAS28 $=28$-joint Disease Activity Score. 

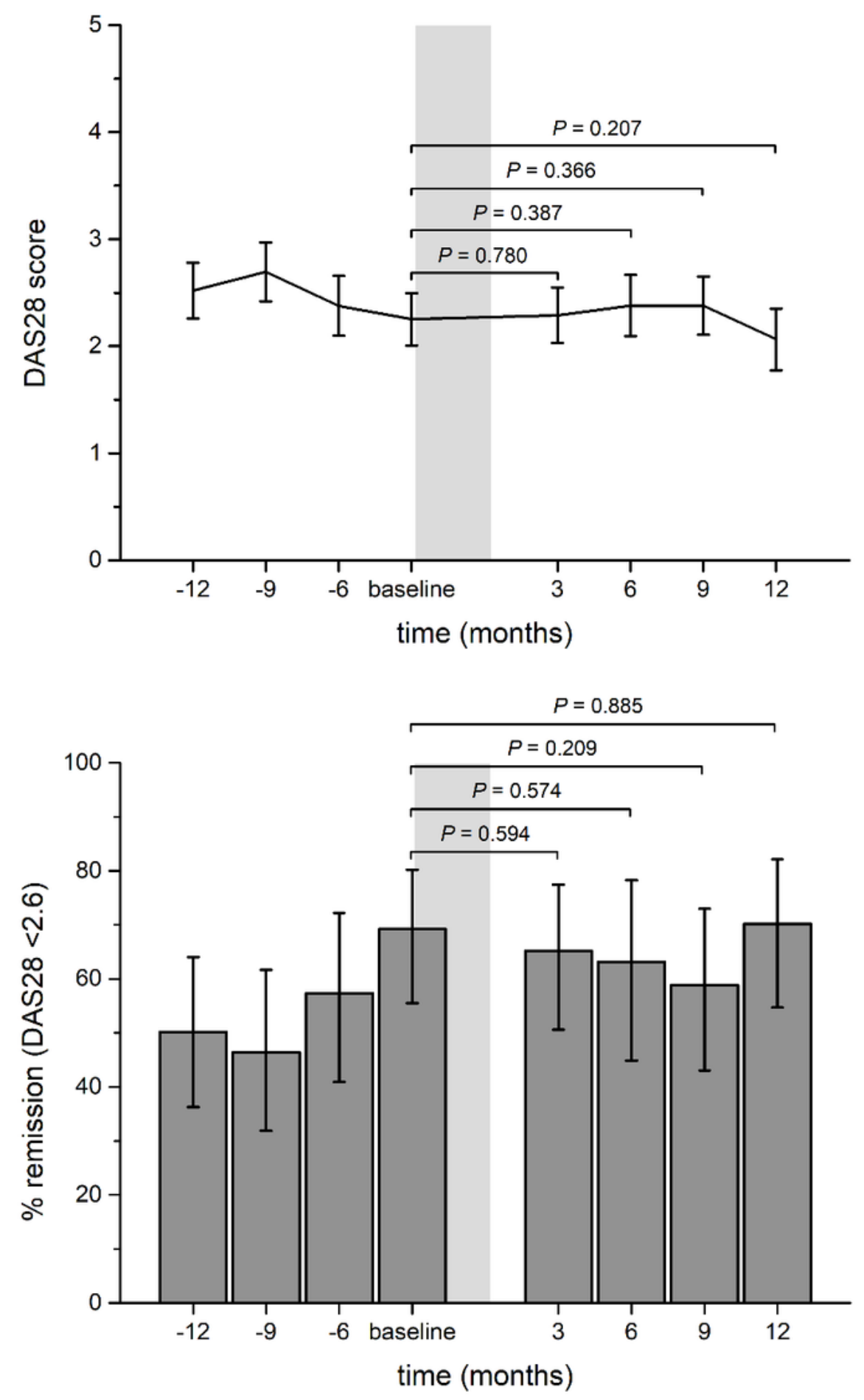

Figure 2

Disease activity before and after the switch. Top panel: Mean DAS28 scores over time. Bottom panel: Percentage of patients in DAS28 remission (DAS28 $<2.6$ ) over time. Error bars are $95 \%$ Wald confidence intervals. P-values are based on post-hoc analyses of difference from baseline with Fisher least significant difference correction for multiple comparisons. Light grey area indicates the time of switch. DAS28 $=28$-joint disease activity score. 

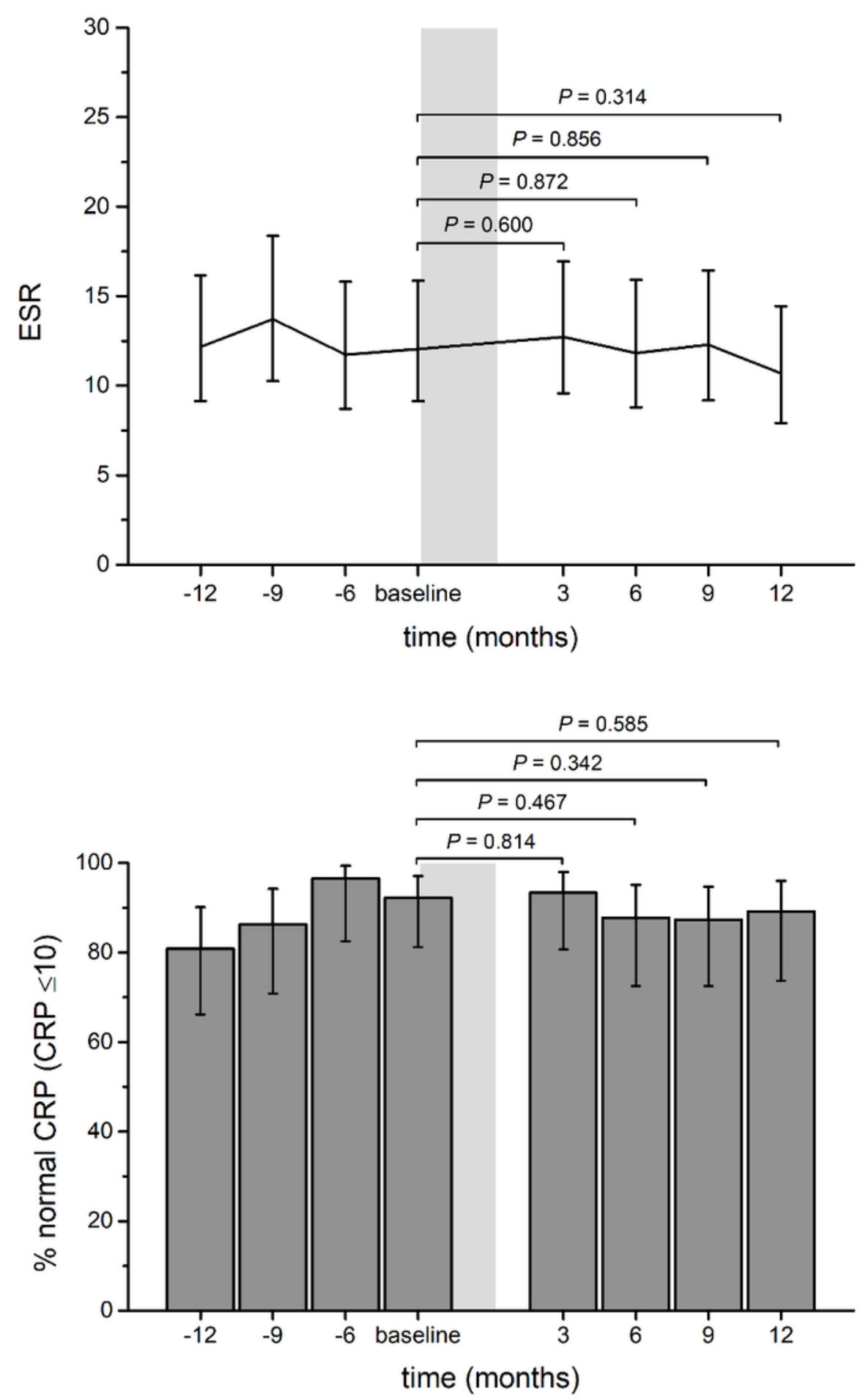

Figure 3

Markers of inflammation before and after the switch. Top panel: Mean ESR values over time. Bottom panel: Percentage of patients with a normal CRP value (CRP $\leq 10)$ over time. Error bars are $95 \%$ Wald confidence intervals. P-values are based on post-hoc analyses of difference from baseline with Fisher least significant difference correction for multiple comparisons. Light grey area indicates the time of switch. $\mathrm{ESR}=$ erythrocyte sedimentation rate, $\mathrm{CRP}=\mathrm{C}$-reactive protein . 

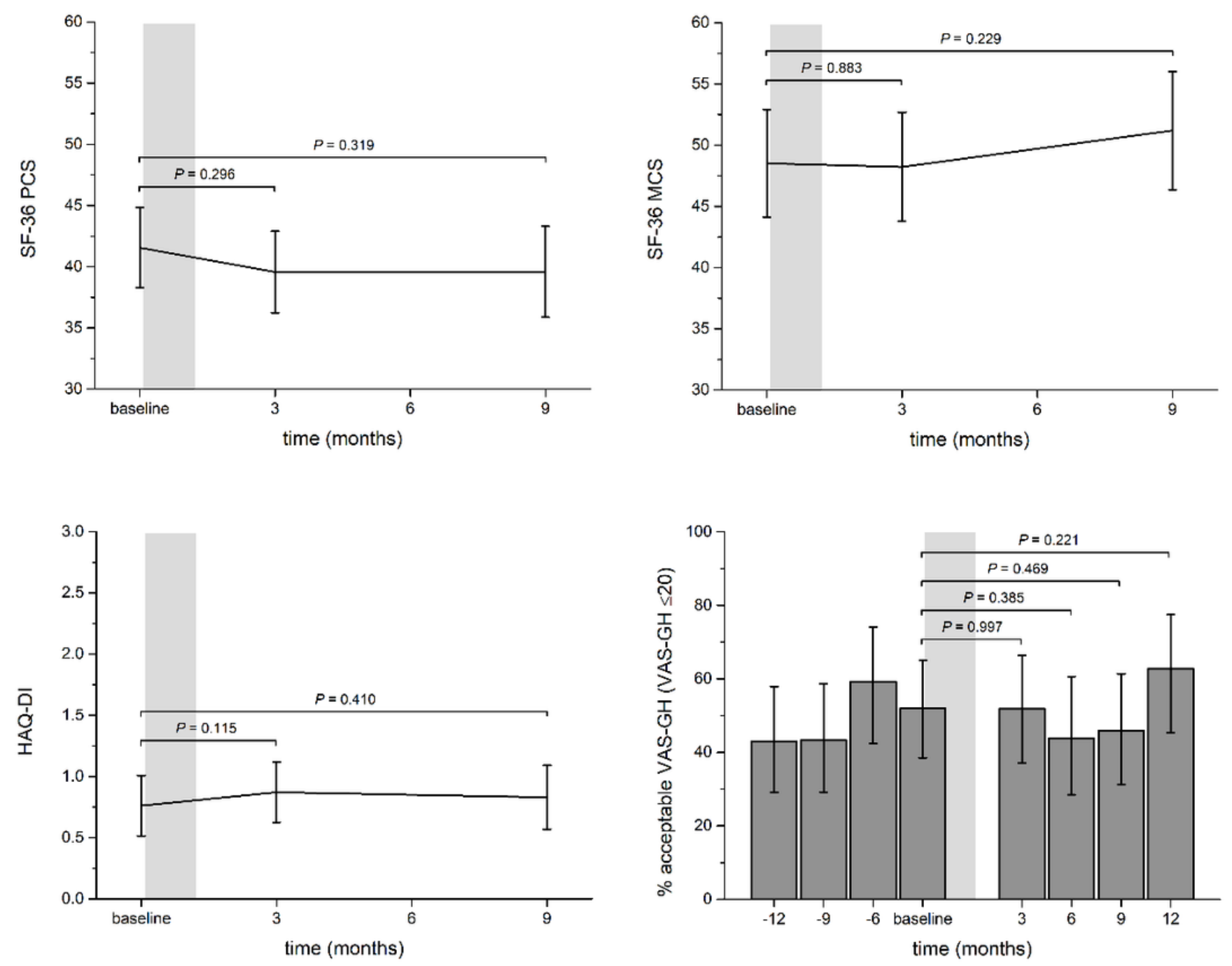

\section{Figure 4}

Patient-reported outcomes before and after the switch. Top left panel: Mean physical health-related quality of life. Top right panel: Mean mental health-related quality of life. Bottom left panel: Mean functional disability over time. Bottom right panel: Percentage of patients with acceptable general health (VAS-GH $\leq 20$ ). Error bars are $95 \%$ Wald confidence intervals. P-values are based on post-hoc analyses of difference from baseline with Fisher least significant difference correction for multiple comparisons. Light grey area indicates the time of switch. SF-36 PCS = Short Form-36 Physical Component Summary, SF-36 MCS = Short Form-36 Mental Component Summary, HAQ-DI = Health Assessment Questionnaire Disability Index, VAS-GH = visual analogue scale of general health.

\section{Supplementary Files}

This is a list of supplementary files associated with this preprint. Click to download.

- Additionalquestionnaireinthestudysample.docx 